\title{
Research in Action: Evidence-Based Strategies to Improve One-to-One Teaching
}

\author{
Jennifer Blackwell \\ Jacobs School of Music \\ Indiana University
}

\section{ABSTRACT}

This article is an application of learning theory to the studio teaching environment, discussing various evidence-based educational practices that can be applied for teachers with instrument-specific content knowledge, but little or no pedagogical training. Learning theories such as social constructivism, instructional scaffolding, and self-regulation are presented with practical examples of how they can be applied in the studio teaching environment. In addition, issues of student-teacher relationship and studio culture within the unique context of applied teaching serve to reinforce best practices and improve overall teaching.

Keywords: Pedagogy, studio teaching, social learning, self-regulation, instructional scaffolding 


\section{SARAH'S STUDIO}

Imagine Sarah, a recent bachelor of music performance graduate, has taken a job teaching a large private flute studio within a respected community music school, with students ranging from absolute beginners to high school students preparing for collegiate auditions. She studied flute diligently all throughout her degree, and is excited to try her hand at teaching. Sarah teaches weekly one-to-one lessons to every student, group studio classes, and chamber music to interested students. After a few months, however, Sarah is concerned that she is doing something wrong: her students seem bored and unmotivated, and they are not progressing as quickly as she had hoped. Sarah is very confident in her ability to teach her students flute-specific skills, but she just doesn't feel like she's really getting through to them. Sarah tries giving lectures about practicing, talking to parents about practice habits, providing candy to students who improve, but none of this works well. Eventually, Sarah finds herself losing students. "What am I doing wrong?" Sarah wonders.

Although Sarah's story is fictional, she is certainly not alone in the world of studio teaching, particularly as a young teacher working within a community school context. The implicit assumption in university education is that because music students are taught in the private lesson environment, they will be able to absorb pedagogical models for their own teaching (Frederickson, Gavin \& Moore, 2012; Frederickson, 2007, p. 327). Indeed, the oneon-one lesson is how the vast majority of people like Sarah learn to play a musical instrument (Brand, 1992, p.3; Schmidt, 1992, p.32; Abeles, 2011, p.19; L'Hommedieu, 1992, p. 100; Nolan, 2012, p.3), but few receive systematic, formal training on teaching in the university or conservatory context. Music graduates like Sarah receive some training in what to teach, but not how to teach in the studio environment (Parkes, 2009, p. 71). As a teacher in a non-university context, Sarah is unlikely to have access to professional development opportunities to improve her studio teaching. Because the applied studio is a teaching environment or context, not a strategy or methodology in itself, it is important to develop context-specific teaching strategies, and thus Sarah needs to seek out reliable sources of information (Kennell, 2002, p. 245). So, what can Sarah do to improve her teaching? What are evidence-based educational practices could benefit her students, and which of those practices do the best artist-teachers in our field already employ? Research highlighting the importance of rapport with students, social learning and community, instructional scaffolding, and self-regulation provide an important basis for understanding evidence-based practices in studio teaching.

\section{HOW DOES STUDIO TEACHING WORK?}

It is important to note that the music studio is a unique and highly specialized environment. Traditionally, learning in the private studio functions under an apprenticeship model, in which the knowledge of the teacher is passed down to the student 


\section{Blackwell Research in Action: Evidence-Based Strategies}

over many years of study. In this model, the student will most likely teach in the way they were taught by their own teachers (Frederickson, Gavin \& Moore 2012; Hyry-Beihammer, 2010, p. 162). Applied teachers are "members of an important oral tradition in which personal experience and historical anecdote form the basis of contemporary common practice," and "performance expertise is passed from one generation of performers to the next through the lineage of personal experience and the applied lesson," (Kennell, 1992, p. 5). This model allows for 'schools' of playing, as studying with one particular teacher makes one an insider to that particular tradition.

While it is not necessarily problematic to teach like one's own teacher, only using the strategies by which one was taught can be very limiting. Since students will have different personalities, goals, technical problems, and learning tendencies, it is unlikely that one method of teaching will work for everyone. But, since specific training for teaching in the applied studio is not common practice, and the studio environment continues to be under-researched, it is difficult for people like Sarah to know what else to do (Call, 2000, p. 8; Kennell, 2002, p. 244; L'Hommedieu, 1992, p. 100; Sogin \& Vallentine, 1992, p. 32). There is, however, a growing body of literature that can provide direction for practicing studio teachers (Clemmons, 2009; Duke \& Chapman, 2011; Gholson, 1998; Montemayor, 2008).

\section{RAPPORT}

Perhaps the most important thing Sarah can do to motivate her students is foster a positive student-teacher relationship. Luckily, the interactions between student and teacher have attracted considerable attention from music researchers as a unique element of one-to-one study (Kennell, 2002, p. 252). Research findings show that the quality of relationship between student and teacher may have a dramatic effect on overall student success (Abeles, 2011, p. 20).

Clemmons's (2009) research focused on master singing teachers who were known for building strong relationships with their students, and concluded that these relationships were essential in the lesson environment (p. 264). Further research suggests that teachers who are successful in creating good relationships have a high level of content knowledge and confidence, establish a non-threatening learning environment, have high expectations, and are enthusiastic (Clemmons, 2007, p. 277-279).

For Sarah, content knowledge is not a problem, so she can focus on the other elements important to studio teaching. Rather than lecturing students when she feels they are not progressing fast enough, Sarah could express curiosity about how the student is practicing on their own, and help the student choose better learning strategies. Sarah can keep her high expectations for student progress, provided that they are grounded in a supportive environment. Sarah has already expressed enthusiasm for learning to teach, so she should share that enthusiasm with her students. She could talk to students about the 
pieces she is learning, and how excited she is to learn new music. She could share her favorite recordings, and invite students to share theirs. Gestures as simple as eye contact, smiling, and welcoming the student to the lesson can set the stage for productive learning (Clemmons, 2007, p. 280). By creating a comfortable and supportive learning environment, Sarah can help her students while developing positive personal relationships.

\section{SOCIAL LEARNING AND COMMUNITY}

Since Sarah has a large studio to work with, she can benefit from applying social learning techniques with her students. Championed by psychologist Lev Vygotsky, Social Constructivism proposes that knowledge is socially constructed, and thus all learning must take place in interactions between people (Powell \& Kalina, 2009, p. 243). Central to this theory is the zone of proximal development, which is the area between a student's current skill level and activities or skills they can execute with the assistance of a teacher (Gholson, 1998, p. 539).

The research literature provides a few important examples of social learning in action. Nolan (2012) describes Frederick Hemke's "buddy system," in which a less experienced, younger studio member is paired with an older, more experienced member, where both can benefit from an ongoing dialogue of constructive criticism (p. 104). In describing this system, Nolan (2012) notes:

Lesson buddies are expected to meet during the week, to go over lesson material, and provide constructive criticism to each other. They observe and listen to each other's lessons and are expected to contribute to the lesson through this teaching approach. (p. 104)

In addition, Nolan noted a sense of family within Hemke's studio, in which students are expected to care for and respect each other (p. 106). Eugene Rousseau, also featured in Nolan's thesis, encourages his students to model their own practice strategies after the studio mates whom they admire most, in an effort to help them discover their own best strategies (p. 134). In Sarah's studio, this might include pairing students for lessons, or developing a mentorship program where older students help their younger peers. From a social learning perspective, the development of a culture that defines roles/expectations for both the teacher-student relationship and relationships between studio members, and the standards that students are expected to uphold, is central to successful learning.

Montemayor's (2008) ethnography of a successful applied flute studio is particularly helpful, as it highlights the importance of interpersonal relationships between students and a broader studio community. He noted that his primary research subject, Jennifer Moran, was highly successful in providing different instruction for different learners, which he calls important teacher 'caring' behaviors (p. 292). Particularly important was the 'flute culture' within the studio; he found that Moran expressed a significant solidarity with and affinity for her students, particularly through a flute choir in 
which all students participated (p. 297). Montemayor found that being involved in this unique studio culture served to "reinforce a strong sense of identity among these students" (p. 293).

Sarah's community music school presents an ideal environment for social learning. She could start a flute ensemble, or perhaps develop chamber music groups with other studios within the school. She could arrange studio recitals, social activities, and an environment that encourages studio members to interact with and learn from each other.

\section{SCAFFOLDING}

According to Kennell (2002), the applied lesson environment is an ideal example of psychologist Lev Vygotsky's notion of joint problem solving. In the applied studio, the student can develop musical skills through problem solving activities, supported by the teacher (Kennell, 2002, p. 8). So, if Sarah helps her students solve problems in the lesson, she can help them learn to use self-problem solving strategies in the practice room throughout the week. This is followed by another joint problem solving strategy in the next lesson, which serves to help the student reach new levels.

Wood, Bruner, \& Ross (1976) first coined the term "scaffolding strategy" to describe the teacher intervention in the joint problem solving process. Their theory involves a process of 'scaffolding,' which helps the student to solve a problem, carry out a task, or achieve a goal that they would currently be unable to do on their own (Wood, Bruner \& Ross, 1976, p. 90). In this model, the teacher provides support to help students achieve musical goals they are currently unable to reach without assistance. An ultimate goal of scaffolding student learners is to show them how to make well-formed decisions in current and future learning situations on their own (Nolan, 2012, p. 78).

In keeping with scaffolding, the ultimate goal of the studio teacher is to gradually develop student independence, both through increasing student confidence and their ability to use independent problem-solving strategies in their own practice time (Kennell, 1992, p. 15). Kennell, citing the work of Wood, Bruner, and Ross (1976), developed six categories of scaffolding that are important to the applied lesson environment in an "expert-novice teaching learning context:

1. Recruitment-the interaction between teacher and student.

2. Marking critical features-identification and correction of errors.

3. Task manipulation-simplifying the task to help the student start the scaffolding process.

4. Demonstration - the teacher plays in the lesson to model good playing or demonstrate the student's errors.

5. Direction maintenance-the teacher sets goals for upcoming lessons or performances.

6. Frustration control—the teacher recognizes and supports the student through the 
struggles to improve" (Kennell, 2002, p. 245).

Sarah can apply all six of these scaffolding criteria in her teaching, and several relate to other elements of teaching already discussed. Sarah can highlight performance problems, and provide simplified tasks to help students solve them. Perhaps a difficult interval leap could be practiced without regard for rhythm, or a tricky technical passage could be broken down to switching fingerings between individual notes. In providing instructional scaffolding for her students, Sarah helps them to develop higher levels of skill and avoid the frustration of unproductive practice. Many of the elements of scaffolding in the studio environement connect directly to self-regulated learning, which is an essential element in any productive learning environment.

\section{SELF-REGULATION}

Sarah's struggles with student engagement may also point to a lack of selfregulation in student learning. From a social cognitive perspective, self-regulation can be defined as "self-generated thoughts, feelings, and actions that are planned and cyclically adapted to the atainment of personal goals" (Zimmerman, 2000, p. 14). In the applied studio, this would involve identifying specific performance goals-perhaps a specific piece to be learned. The self-regulated student would identify steps to learning that particular piece, monitor the success of practice time, and devise strategies for any problems that may arise. Those learners, in turn, use increasingly sophistocated strategies and goal setting approaches as they become more self-regulated over time. Few if any students are become efficient self-regulated learners without the support of their teachers, however, and thus teachers must help their students develop self-regulation strategies. McPherson, Nielsen, and Renwick's (2012) ${ }^{1}$ chapter on self-regulation and music suggests a number of strategies for the applied teacher. Based on Zimmerman's (2000) social-cognitivist perspective, the authors propose six dimensions of self-regulation: motive, method, time, behavior, physical environment, and social aspects (p. 359). In their view, self-regulation begins socially and shifts over time to a self-oriented process, moving through four stages: observation, emulation, self-control, and finally self-regulation (p. 366).

\section{MOTIVATION}

Initially, student motivation has to be directly reinforced by the teacher, gradually moving toward self-motivation over time (McPherson, Nielsen, and Renwick, 2012, p. 359). In Sarah's studio, this might involve allowing students to self-select pieces from a list of repertoire that cover a specific set of pedagogical goals. This way, Sarah can ensure all

\footnotetext{
${ }^{1}$ The terminology used to delineate the following sections (Motivation, Method, Time, Behavior, Physical Environment, and Social Aspects) is drawn from McPherson, Nielsen and Renwick's (2012) chapter on self-regulation; these terms are used to describe what most musicians would colloquially refer to as the various aspects of "practicing" effectively.
} 
students are playing pieces that they choose, while still covering a core of fundamental technique. Over time as technical skills develop, students could choose their own repertoire more autonomously, picking pieces they enjoy and are reflective of their performance goals.

McPherson, Nielsen, and Renwick (2012) also suggest limiting extrinsic rewards, as they can undermine the student's intrinsic motivation to learn music. So, while Sarah has tried to use candy as a motivator for student progress, she is unwittingly undermining her students' long-term motivation for music learning. Students come to expect candy as a reward for hard work, and may be demotivated to work if they do not receive this reward. If Sarah allows students to learn music they enjoy, music making itself can act as an intrinsic reward.

\section{METHOD}

Often, when students are struggling to learn a piece of music, the advice they are given is to "go practice." Practice is not a self-evident process however, and thus students must have some guidance in how to practice well. To help students develop effective practice methods, we can teach rehearsal strategies, elaboration strategies, organizational strategies, and critical-thinking strategies (McPherson, Nielsen, and Renwick, 2012, p. 362). Rehearsal strategies involve identifying, isolating, and focusing effort on passages that have not yet been mastered (p. 362). So, the studio teacher must guide the student through this process, starting with modeling good playing and practice techniques. The student would then copy these techniques, eventually developing the ability to apply them to similar situations. Finally, the self-regulated student can use effective learning strategies on their own in a variety of contexts.

\section{TIME}

Similar to being told to "practice," as a solution to performance problems, students are often given a prescribed amount of time to practice each day. Many students "put in their time" with the instrument, practicing inefficiently and anxiously watching the clock for quitting time. Rather than emphasizing time spent, self-regulated learners can emphasize mastery criteria (McPherson, Nielsen, and Renwick, 2012, p. 368). So instead of practicing for thirty goalless minutes per day, the student could set a goal of mastering a certain passage, increasing a tempo, or developing musical phrasing. In this scenario, Sarah could model how to choose a manageably sized goal for a particular practice session, gradually allowing the students to set their own goals as their sense of what they can accomplish in a given period of time improves.

\section{BEHAVIOR}


Sarah feels that her students are not progressing quickly enough, and she has discussed practicing with them, so what else could be going wrong? The students may not be able to effectively identify problems in their practice or performance, and thus their practice time is not used efficiently. The self-regulated learner is able to see when they do not understand something, or when something is particularly challenging (McPherson, Nielsen, and Renwick, 2012, p. 368). Sarah could ask guiding questions in the lessons, which would help her determine if the student was hearing problems the same way she is. Sarah could then highlight specific performance problems and solutions, with the ultimate goal of instilling this sort of thinking in her students.

\section{PHYSICAL ENVIRONMENT}

The space in which students practice can be an important factor in their educational development. Both students and parents need to be aware, for example, that the learning environment is essential for student growth, including a quiet, distraction-free practice space (McPherson, Nielsen, and Renwick, 2012, p. 371). Sarah can model this environment in her own studio by providing a clean, quiet, and organized space for learning, as well as modeling good performance habits such as proper posture. She can discuss what makes a good practice space at home, allowing the students to develop an environment that works for them.

\section{SOCIAL ASPECTS}

Since social factors play a key role in student learning, parents are essential in the self-regulation of student learners. This includes monitoring practice, displaying interest in student progress, and moral support for learning (McPherson, Nielsen, and Renwick, 2012, p. 372).

Sarah herself can play an important social role, including praising students for good practice habits, model good habits herself, and displaying joy in learning. Social aspects of learning can also include studio ensembles, duets with the teacher, and other performance opportunities in which students can develop motivation from interactions with others.

\section{SARAH'S STUDIO REVISITED}

Sarah has worked hard to include proven teaching strategies in her community music school studio, and she is seeing positive results. She pays much more attention to her students own musical interests, and allows them to pick repertoire accordingly. Sarah finds that when students feel a sense of ownership and pride for what they are learning, she no longer has to remind students to practice, nor does she have to talk to parents about student effort.

When a student is frustrated by a piece, Sarah spends lesson time talking through how she would practice the piece herself. She models her practice strategies, and explains 
why she has chosen to learn this passage in this way. She makes sure to always be supportive of her students when they struggle, and to help them overcome their problems with specific solutions. Over time, Sarah asks her students to develop their own plans for practicing, helping only when the students seem stuck.

Sarah has started an elective flute choir for her studio, in which different parts are available for the current ability level of each student. A ten-year-old flutist may be playing a quarter note ostinato next to an eighteen year old playing a complex melody. She finds that the older students enjoy helping the younger students and taking on leadership roles, while the younger students improve rapidly through hearing excellent playing all around them.

Sarah also offers group lessons for students of similar ability levels, which provides a sense of community among her students. For those who choose to take private lessons, Sarah makes sure to play duets with her students, which both models good playing habits and motivates the students. Not only does she have better personal relationships with her students, but they are also progressing more quickly, and exhibit a genuine love of music making.

Sarah's story has an important message: we do not need to reinvent studio teaching, but we can improve it. This model has been the cornerstone of music education practice for centuries, and it has been enormously successful in many contexts, but studio teachers still need support in developing best practices for their work. Research highlighting the importance of rapport with students, social learning and community, instructional scaffolding, and self-regulation provides an important basis for understanding evidencebased practices in studio teaching, and an important resource for practicing studio teachers. Until significant educational reform provides adequate training for performance students who may become studio teachers, teachers like Sarah will have to seek out resources on their own to improve their teaching. We are in a position, however, to improve the studio teaching and learning environment with methods backed by the best research available today.

\section{REFERENCES}

Abeles, H. (2011). Designing effective music studio instruction. In P. Madura WardSteinman (Ed.), Advances in Social-Psychology and Music Education Research (pp. 1927). Burlington, VT: Ashgate.

Brand, M. (1992). Voodoo and the applied music studio. The Quarterly Journal of Music Teaching and Learning, 3(2), 3-4.

Call, R. (2000). Tuba studio teaching: Three case studies of highly effective teachers (Unpublished doctoral dissertation). The University of Utah, Salt Lake City. 
Clemmons, J. (2009). The importance of being earnest: Rapport in the applied studio. College Music Symposium, 49(50), 257-264.

Duke. R. A. \& Chapman, D. (2011). Changing learners: The nature of expertise in music teaching. In P. Madura Ward-Steinman (Ed.), Advances in Social-Psychology and Music Education Research (pp. 29-38). Burlington, VT: Ashgate.

Frederickson, W.E., Gavin, R.B., \& Moore, C. (2012). Attitudes of members of the national association of college wind and percussion instructors toward their own and their students' teaching of applied music lessons. Journal of Music Teacher Education, 21(41), 41-53.

Frederickson, W.E (2007). Music major's attitudes toward private lesson teaching after graduation: A replication and extension. Journal of Research in Music Education, 55(4), 326-343.

Gholson, S.A. (1998). Proximal positioning: A strategy of practice in violin pedagogy. Journal of Research in Music Education, 46(535), 535-545.

Hyry-Beihammer, E.K. (2010). Master-apprentice relation in music teaching: From a secret garden to a transparent modeling. Nordic Research in Music Education, 12, 161-178.

Kennell, R. (2002). Systematic research in studio instruction in music. In R. Cowell \& C. Richardson (Eds.), The New Handbook of Research on Music Teaching and Learning (pp. 243-256). New York: Oxford University Press.

Kennell, R. (1992). Toward a theory of applied music instruction. The Quarterly Journal of Music Teaching and Learning, 3(2), 5-16.

L'Hommedieu, R. (1992). The management of selected educational process variables by master studio teachers in music performance. (Unpublished doctoral dissertation), Northwestern University, Evanston.

McPherson, G.E., Nielsen, S.G., \& Renwick, J.M. (2012). Self-regulation interventions and the development of music expertise. In H. Bembenutty, T. J. Cleary, \& A. Kitsantas (Eds.), Applications of self-regulated learning across diverse disciplines: A tribute to Barry J. Zimmerman (pp. 355-382). Charlotte, NC: Information Age Publishing. 
Blackwell Research in Action: Evidence-Based Strategies

Montemayor, M. (2008). Flauto: an ethnographic study of a highly successful private studio. International Journal of Music Education, 26(4), 286-301.

Nolan, J. (2012). Fostering artistry and pedagogy: Conversations with artist-teachers Frederick Hemke, Eugene Rousseau, and Donald Sinta. (Unpublished doctoral dissertation). University of British Columbia, Vancouver.

Parkes, K.A. (2009). College applied faculty: The disjunction of performer, teacher, and educator. College Music Symposium, 49(50), 65-76.

Schmidt, C.P. (1992). Systematic research in applied music instruction: A Review of the literature." The Quarterly Journal of Music Teaching and Learning, 3(2), 32-45.

Sogin, D.W., \& Vallentine, J.F. (1992). Use of instructional time and repertoire diversity in university applied music lessons. The Quarterly Journal of Music Teaching and Learning, 3(4), 32-36.

Powell, K.C. \& Kalina, C.J. (2009). Cognitive and social constructivism: Developing tools for an effective classroom. Education, 130(2), 241-250.

Wood, D. Bruner, J.S., \& Ross, G. (1976). The role of tutoring in problem solving. Journal of child psychology and psychiatry, 17, 89-100. 